\title{
Comunicar desde lo público: enfoques y perspectivas
}

\author{
Por Lucía Martorelli y Matías Ponce \\ Fotos de Pablo Porciúncula
}

Uno de los tantos significados que podemos darle al término comunicación es el de crear comunidad. No obstante, no todas las comunidades son iguales. Para el tema que nos interesa, podemos diferenciar aquellas comunidades que se guían por intereses privados y aquellas que buscan intereses colectivos. Los asuntos públicos obligan a elaborar una estrategia distinta a la comunicación de las empresas privadas. El sector público y los actores políticos demandan una gestión comunicacional que se convierta en un aporte para mejores políticas públicas y la contribución a la calidad del régimen democrático.

Hoy convivimos con diversos niveles de profesionalización de las comunicaciones en el ámbito público.

¿Existe una política de estado en materia de comunicaciones? ¿Cómo interactúan los actores políticos con los comunicadores de gobierno? ¿Cuál es la cocina de la imagen de un gobierno, de un gobernante o de un político? ¿Qué uso de las TIC realiza el gobierno para mejorar su comunicación con la ciudadanía? ¿Cuál es el rol de un comunicador en el gobierno? ¿Qué lógicas de comunicación tiene la ciudadanía? ¿Qué rol juega hoy la comunicación en red? ¿Cómo se realiza la gestión de las comunicaciones en lo público no estatal? ¿De qué manera se utilizan las TIC en movimientos de participación ciudadana, sociales, etc.? ¿Cómo ha incidido ello en la comunicación política? En el presente artículo pretendemos dar respuesta a esas interrogantes, que se han convertido en preguntas centrales para los comunicadores que trabajan en este contexto de reforma del Estado y del sector público no estatal. Lo que sigue son apuntes y reflexiones para comprender la especialidad en comunicar desde lo público.

Sociedad civil y comunicación política

El debilitamiento de los Estados de Bienestar ha obligado a repensar, durante los últimos años, a los gobiernos y a los diferentes actores políticos y sociales, en nuevas alternativas para llevar adelante los asuntos públicos y, consecuentemente, en nuevos modelos de desarrollo para las sociedades. 


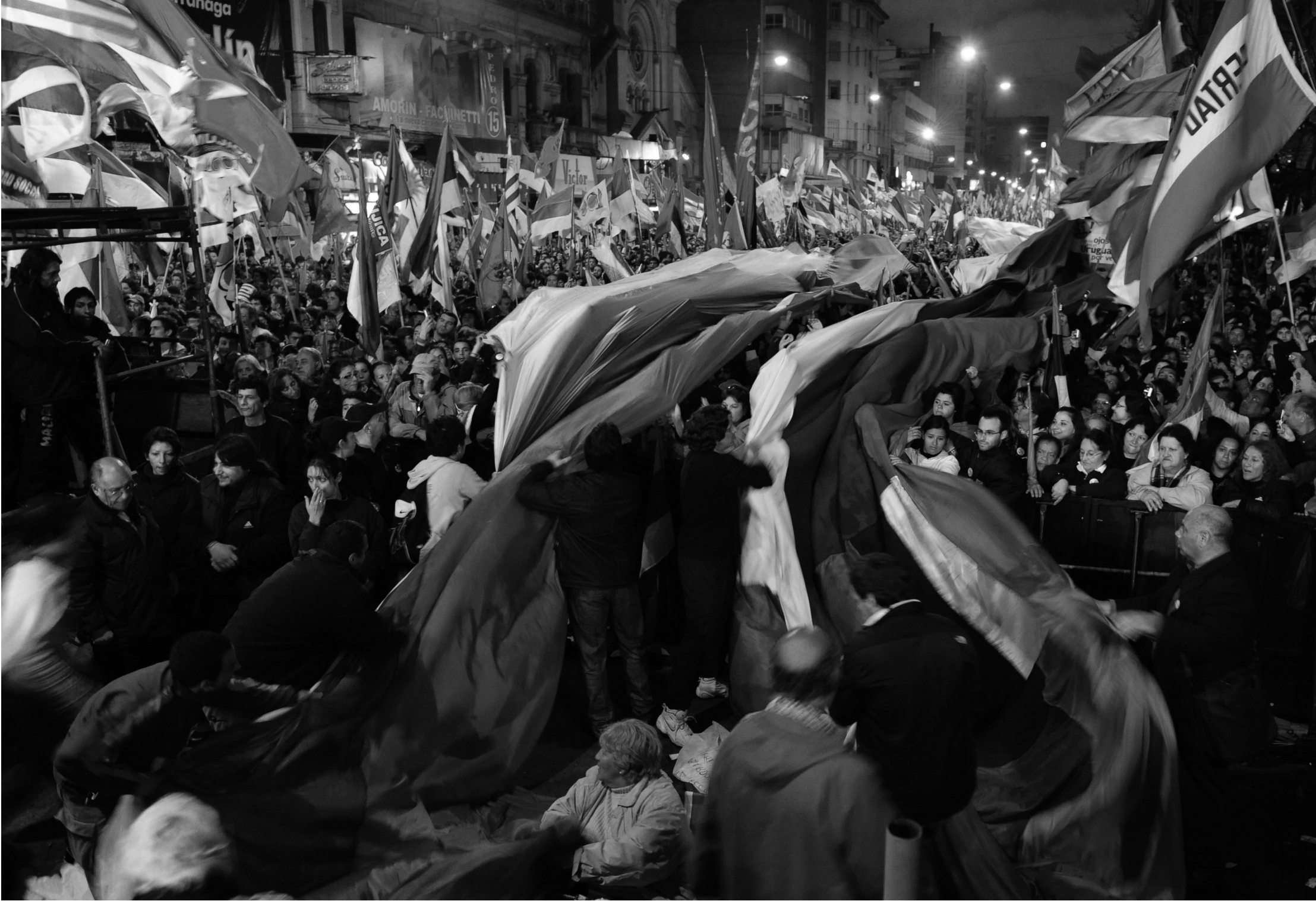

A partir de estas transformaciones la eficiencia, la legitimidad y el consenso pasan a ser los conceptos claves para la gobernabilidad democrática, así como para la gobernanza. Esta última hace referencia a una nueva forma de gestión "inclusiva" de las políticas públicas, en donde se trasladan responsabilidades hacia la sociedad civil, en un contexto en donde nuevos actores no partidarios -sindicatos, asociaciones, organizaciones no gubernamentales, fundaciones, comisiones barriales, etc.- se incorporan en forma activa a la realidad de la política nacional.

Estos nuevos actores, por un lado luchan por la inclusión y el poder en el sistema de la organización política y, por otro lado, también se esfuerzan para influir directamente en el sistema político. De esta manera, las organizaciones de la sociedad civil usan y amplían el discurso y los espacios públicos.

Asimismo, los actores colectivos contemporáneos ven que la creación de identidad supone un conflicto social en lo que se refiere a la reinterpretación de las normas, a la creación de nuevos significados y al desafío de la construcción social de los límites mismos, entre los dominios de la acción pública, la privada y la política. La comunicación política y la configuración de lo público adquieren entonces una relevancia diferente, con la participación de diversidad de actores que requieren de estrategias comunicacionales específicas para incidir en los asuntos públicos. La creación de la agenda pública ya no surge únicamente de los ámbitos gubernamentales y esta-
Foto::

Bandera de retazos

confeccionada a partir de una convocatoria vía Internet, campaña presidencial, $21 \mathrm{de}$ octubre de 2009. 
Lucía Martorelli:: (Montevideo, 1971) es candidata a doctora en Ciencia Política (Universidad de San Martín, Bs. As.), master en Políticas Públicas (ORT) y licenciada en Ciencias de la Comunicación Social (Universidad Católica del Uruguay). Es investigadora y docente del Centro Latinoamericano de Economia Humana (CLAEH) y docente de la Universidad

Católica del Uruguay. Es responsable de

comunicación del Programa de Modernización de la Institucionalidad para la Gestión y Planificación Ambiental, del Ministerio de Vivienda, Ordenamiento Territorial y Medio Ambiente (MVOTMA). Es socia consultora de Activa Comunicación Estratégica. Se ha desempeñado profesionalmente en organizaciones tanto públicas como privadas.

os términos "disruptivos, confrontativos y convencionales" fueron mencionados y analizados en el trabajo "Derechos Humanos en el Uruquay 1985-2007. Temas, actores y visibilidad pública (Ordoñez, Martorelli, Santangelo), llevado a cabo por CLAEH-Konrad Adenauer, con relación al estudio con las estrategias de acción de las organizaciones defensora de los Derechos Humanos. tales, al tiempo que se han diversificado los actores, los canales y los mensajes de la comunicación política.

Comunicación política, acción colectiva y movimientos sociales

La comunicación política es aquella que posibilita que ciertos actores sociales expresen, en público, sus opiniones sobre lo político, que configura el espacio público y su agenda de temas. Dentro de la literatura de la acción colectiva de la sociedad civil y de los movimientos sociales se pueden distinguir tres enfoques fundamentales, que analizaremos desde el punto de vista de la comunicación.

Iniciemos con el enfoque que sostiene que el surgimiento de los movimientos sociales responde a un cambio en la estructura de oportunidades políticas (con autores como Tilly, Tarrow y McAdam). Las denominadas estructuras de oportunidades hacen referencia directa a la importancia del sistema político para crear oportunidades de acción colectiva y a la interacción entre los movimientos sociales y la política institucionalizada. Se trata de momentos en donde la esfera pública se amplía, tanto por la incorporación de determinada temática en la agenda o de nuevos actores como por el cambio de estrategia o de discurso de los mismos. En esas instancias, los actores de la sociedad civil pueden reforzar su presencia y posicionamiento público, negociar la incorporación de nuevas temáticas en la agenda política, aliarse con otros actores estratégicos $\mathrm{y}$, fundamentalmente, generar mensajes comunicacionales disruptivos, confrontativos o convencionales, ${ }^{1}$ según el impacto público que quieran lograr.

Por otro lado, la apertura de la estructura de oportunidades en la esfera pública hace que aumente el flujo comunicacional de los actores políticos, que se incremente su visibilidad pública frente a la ciudadanía y que se abra un espacio de legitimidad de sus acciones.
La comunicación estratégica de las organizaciones de la sociedad civil juega un rol fundamental, ya que determina la capacidad de adaptación del propio discurso y el aprovechamiento de las oportunidades que se presentan para alcanzar los objetivos de la organización. Los mensajes deben ser adecuados para capitalizar el momento; es clave definir los canales de comunicación, así como identificar aliados y opositores, en esa nueva puerta que se abrió y que posibilita que la organización entre o reaparezca en escena.

Otra de las perspectivas de análisis de la sociedad civil y de la acción colectiva es aquella que pone el foco en las estructuras de movilización, que refieren a los canales colectivos tanto formales como informales, a través de los cuales la gente puede movilizarse e implicarse en la acción colectiva (autores como McCarthy y Zald). Este enfoque también analiza la dinámica organizacional de la acción colectiva. Desde esta perspectiva se puede visualizar a la comunicación como un elemento constitutivo de una cultura organizacional, de una determinada organización interna, una estructura en la toma de decisiones dentro de la organización, en definitiva, de una estructura que sustente la movilización pública.

Para comprender este enfoque podemos ejemplificar con la organización Un techo para mi país, que presenta una estructura de movilización sólida: una metodología de intervención propia, una red de voluntarios jóvenes para la construcción de las viviendas, una organización interna a partir de profesionales de las más diversas áreas y un sistema de financiamiento a través de donaciones. Asimismo, posee una estrategia de comunicación que ha logrado un alto nivel de conocimiento por parte de la población, gracias a su efectiva llegada a los medios de comunicación y a las campañas de recolección de fondos y de construcción de viviendas, que involucra a empresas privadas, instituciones académicas y organizaciones barriales, entre otras. 


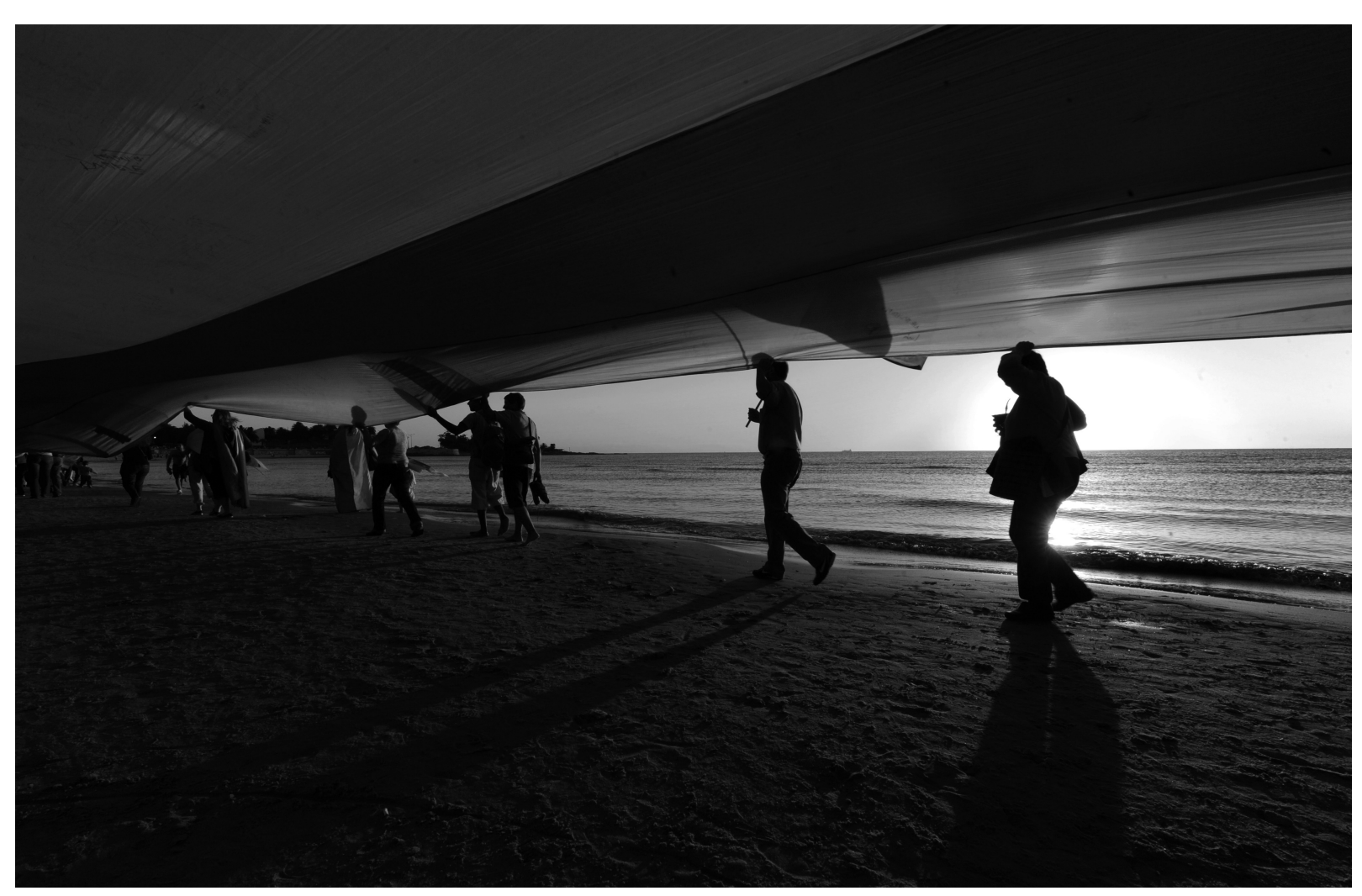

Foto::

"Plantando bandera", actividad convocada vía Internet, campaña presidencial, 18 de noviembre de 2009.
La identidad visual de una organización es también una herramienta de la estructura de la movilización ya que, junto a la comunicación estratégica, es fundamental para trasmitir la personalidad corporativa de la organización.

El tercer enfoque pone atención en los procesos enmarcadores de la acción colectiva en la sociedad civil. Snow -autor que junto a Benford es un referente en este enfoque- define los procesos enmarcadores como los esfuerzos estratégicos conscientes realizados por grupos de personas, para encontrar formas compartidas de considerar el mundo y a sí mismas, que legitimen y muevan hacia la acción colectiva.

Existe un elemento mediador entre oportunidad, organización y acción: los significados compartidos y los conceptos por medio de los cuales las personas tienden a definir sus posiciones con respecto a una determinada situación. Los autores que han estudiado esta perspectiva argumentan que si no existen significados compartidos y socialmente construidos es difícil que se produzca la acción colectiva, aunque exista la estructura de oportunidades adecuada. Se trata de la "dimensión cognitiva", "ideal-valorativa" y “cultural-identitaria” de la acción colectiva. El desafío comunicacional en esta perspectiva radica en cómo generar esos significados compartidos hacia dentro de la organización, en cómo crear consignas que identifiquen a los miembros y que a su vez sumen a más integrantes a las acciones de la organización, y en cómo hacer para que la organización se identifique con determinados valores en la esfera pública.

En términos comunicacionales, se pueden abordar esos aspectos de los procesos enmarcadores de la acción de una organización a partir de la definición de factores motivacionales. Es decir, ¿qué es lo que moviliza a las personas a unirse a la organización, a tomar como propios sus objetivos, a involucrarse en las acciones que propone y a participar en sus distintas formas de movilización? En el caso concreto de Un techo para mi país, ¿qué es lo que hace que cientos de jóvenes construyan viviendas de emergencia o salgan a recolectar fondos en la vía pública?

Asimismo, los procesos enmarcadores suponen el análisis de los factores comunicacionales, como es el
Matías Ponce:

(San José, 1985)

es docente e investigador de la Universidad de la República, la Universidad Católica del Uruguay (UCU) y el CLAEH. Es master en Governance y Politicas Públicas (Complutense de Madrid), master en Ciencia Política (Pontifica Universidad Católica de Chile) y licenciado en Comunicación Ciencia Política y Relaciones Internacionales (UCU).

Consultor Internacional de UNESCO, AECID, OEA, PNUD, BID y gobiernos de América Latina. Ha ejercido cargos de responsabilidad de Comunicación Institucional y Desarrollo Organizacional en organismos públicos en Uruguay. Es socio consultor de Activa Comunicación Estratégica. Coordina el Monitor de estrategias de comunicación del sector público de la UCU. 
caso de los mensajes o los símbolos que se ponen en juego. Se trata de los recursos expresivos que tienen la intención de que las personas participen de la acción propuesta $\mathrm{y}$, por ello, deberán tener en cuenta las características de los públicos a convocar. Pero no solamente: los factores comunicacionales pueden definir un estilo de comunicación que diferencie a la organización de las otras organizaciones.

\section{Nueva política, nueva comunicación}

Hoy en día estamos frente a una modalidad diferente de hacer política: la esfera pública se configura a partir de actores públicos y privados que pugnan por intereses públicos. La agenda política se construye a partir de diversos actores que buscan imponer sus intereses y puntos de vista sobre los diversos problemas que afronta la sociedad.

Los partidos políticos cuentan con la arena electoral para difundir sus ideas en la ciudadanía e imponer sus puntos de vista frente a sus rivales. El voto legitima esas visiones y designa representantes ante los poderes del Estado. Por el contrario, las organizaciones de la sociedad civil esgrimen sus ideales y valores en la arena pública -pero no en la electoral-, buscan adherentes -pero no votos-, diseñan estrategias de comunicación planificadas o espontáneas y buscan ejecutar acciones que las posicionen en las temáticas en las que actúan.

La comunicación es una herramienta fundamental en este esquema multiactoral de la esfera pública. Quienes la utilicen en forma efectiva lograrán aprovechar la estructura de oportunidades que se abre; quienes no, desaparecerán del escenario principal y permanecerán tras bambalinas hasta que la obra finalice.

\section{Estado y comunicación política}

Gobernar es un término que viene del griego kybernán, que significa timonear o guiar, y que está íntimamente relacionado con el concepto de comunicación: crear comunidad. La creación de un concepto de comunidad y guiar las acciones comunitarias, son tareas esenciales de lo que conocemos como comunicación de gobierno. El communication making process del gobierno es el ámbito de las comunicaciones de gobierno: una variable que condiciona al proceso de diseño de las políticas públicas.

La relación entre gobernantes y ciudadanos se construye en un espacio de interacción simbólica y sobre el cual pueden generarse múltiples interrogantes. ¿Cómo generar y gestionar un entorno que sea favorable a una estrategia de gobierno? ¿Cómo mejorar la imagen de un gobierno que debe dar cuenta de su gestión a diversos stakeholders, ${ }^{2}$ todos muy distintos entre sí y con disímiles intereses? ¿Cómo generar mayor accountability y espacios de representación programática a través de una gestión integral de las comunicaciones de gobierno? Muchas preguntas que se resumen en una sola: ¿cómo potenciar las comunicaciones de gobierno como herramienta para la gobernabilidad?

La comunicación y la gobernabilidad

La gobernabilidad democrática puede ser definida como "la capacidad de procesar y aplicar institucionalmente decisiones políticas sin violentar el marco del derecho y en un contexto de legitimidad democrática" (Altman, 2003).

En un contexto de democracia hay que comunicar las decisiones políticas. Por eso, la estrategia de comunicación debe integrar el objetivo de construir una red de asociación temática entre las opiniones de un público específico sobre el emisor, que sea funcional a este último. "La comunicación política pretende movilizar a la ciudadanía para ganar las «batallas por la significación» sobre lo que es y debería ser el «buen orden»" (Rincon, 2004). La estrategia de comunicación del gobierno con la ciudadanía implicará la decisión sobre los medios y canales específicos para el 


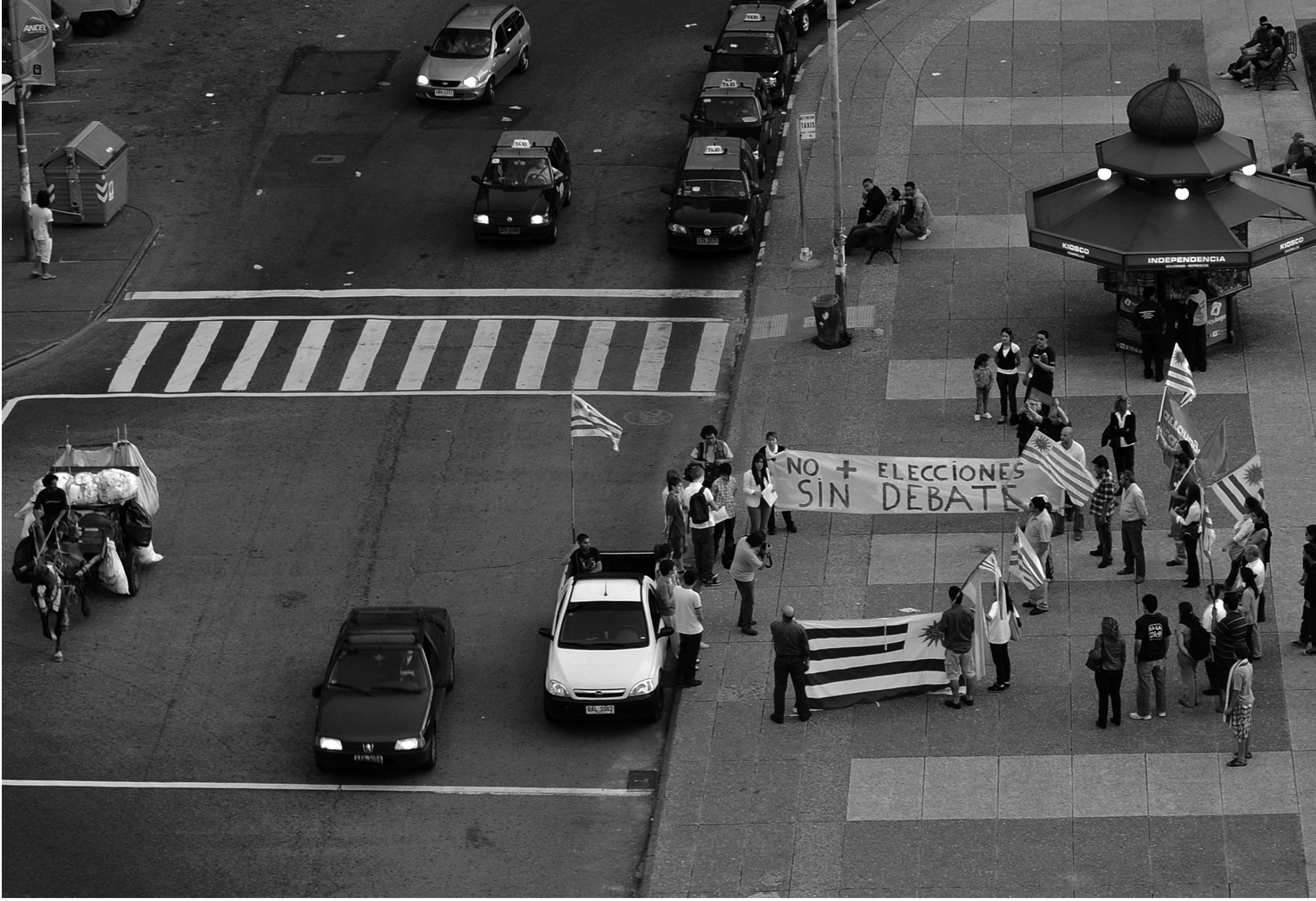

proceso de representación, esto es, el escenario de la comunicación política del que nos refiere Wolton. La estrategia implica decisiones pues "en un gobierno hay muchas cosas que se pueden resaltar. De hecho la gestión de un gobierno abarca un área muy amplia de acción... pero no se puede comunicar todo, hay que saber escoger qué proyectos o acciones -o la imagen de estos- se promueven" (Izurieta, 2000). La estrategia es, entonces, un "plan integral en el que cobra sentido todo lo que hace y deja de hacer el gobierno y todo lo que comunica o deja de comunicar" (Duran, 2000).

La sucesión de comunicaciones del gobierno genera en la ciudadanía una imagen del gobierno. Podemos definir la imagen como un medio "de cadenas o redes de asociaciones que se van construyendo durante un periodo de tiempo y como consecuencia de estímulos que se van acumulando lentamente. Esto lleva a la formación de un mosaico de impresiones que constituyen la imagen" (Caprioti, 2004). ¿En qué ámbitos se produce esa interrelación entre el gobierno y sus distintos públicos? A continuación mencionaremos seis ámbitos de intervención de la comunicación de gobierno como disciplina propiamente tal.

1) La construcción de legitimidad

Una de las principales funciones de la comunicación de gobierno es la de generar esa visión del conjunto social, respetando las distintas opiniones, identidades, territorios, etc. En términos de Weber, quien tenga la jefatura de gobierno necesariamente debe construir legitimidad, esto es, las razones que una persona tiene para ocupar cierto espacio de poder, en
Foto::

"En busca de un debate preelectoral", actividad con vocada vía Internet, campaña presidencial, 25 de noviembre de 2009 . 


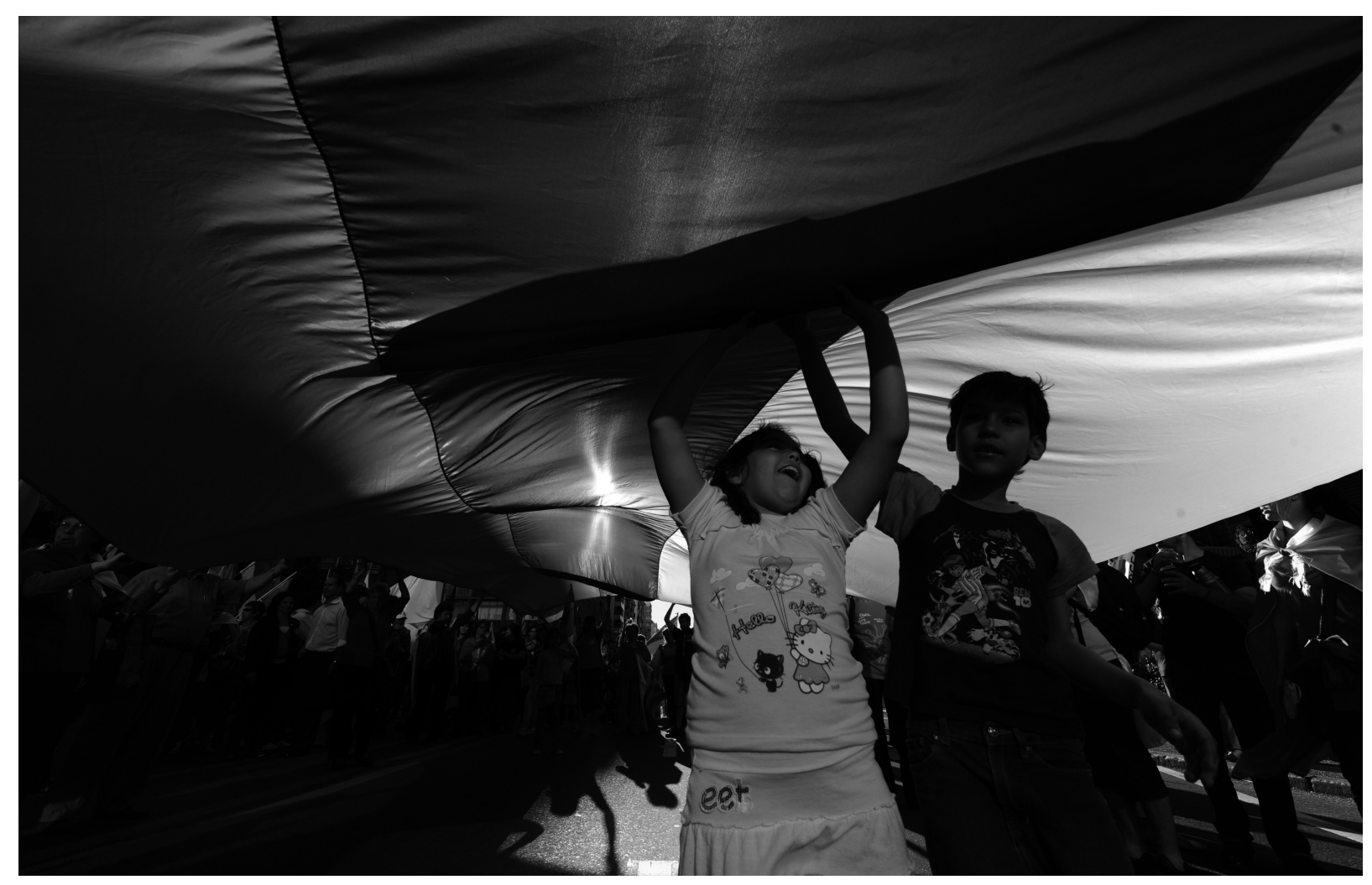

Foto::

"Plantando bandera", activida convocada vía Internet campaña presidencial, 18 de noviembre de 2009 . este caso, la conducción del colectivo ciudadano. Esa construcción de legitimidad puede hacerse apelando a la tradición, como en el caso de un monarca, a procesos legal-racionales, como en la burocracia, o al carisma del propio líder político.

La legitimidad construida debe necesariamente estar ligada a las capacidades de gobernabilidad, es decir, de timonear los procesos sociales, asegurar la toma de decisiones dentro de un determinado marco acordado por la ciudadanía. La gran diferencia con las lógicas de comunicación privadas es que se debe velar por la visión del conjunto social y no por criterios particularistas.

\section{2) El rol de representación}

Un segundo ámbito de la comunicación de gobierno refiere al rol de intermediación entre intereses disímiles dentro de una misma comunidad. Por ejemplo, se instala una inversión extranjera como una planta de celulosa y ello afecta a los derechos de la comunidad local, el Estado debe intervenir al respecto. El mapa de públicos de un gobierno es amplio y debe intervenir estratégicamente sobre cada uno de ellos.
¿A través de qué canales se comunica el gobierno con la ciudadanía? ¿Qué temas prioriza en la agenda pública? La democracia representativa lleva consigo una necesidad de generar espacios de interacción entre los gobernantes y la ciudadanía. La representación política puede definirse como una relación de carácter estable entre ciudadanos y gobernantes, por efecto de la cual los segundos están autorizados a gobernar en nombre y siguiendo los intereses de los primeros, y están sujetos a una responsabilidad política de sus propios comportamientos frente a los mismos ciudadanos por medio de mecanismos institucionales electorales (Cotta, 1986). Para ejercer esa tarea de representación se requiere de un oído muy afinado y de una voz que comunique a diversos públicos la agenda del gobierno. La sintonía con el parecer de la ciudadanía, que tan comúnmente conocemos como opinión pública, requiere ser monitoreada en forma constante por parte de los tomadores de decisión. La velocidad con que viaja la información en nuestra sociedad es prácticamente instantánea, por lo que las imágenes de gobierno están continuamente librando una batalla por ganar la atención ciudadana y lograr una buena percepción. 
David Easton (1993) ejemplifica el proceso del sistema político como un ciclo de retroalimentación de una red política, que va desde el punto inicial del producto hasta el retorno a las autoridades. Estas últimas son, por definición, los acreedores de productos: la retroalimentación debe volver a ellas si se quiere que resulte eficaz para enfrentar la tensión. Para aportar a la fluidez del proceso, el autor utiliza la metáfora de una "caja negra" que debe tender lazos con la ciudadanía, escuchando sus características, intereses y necesidades. Pero, por otro lado, tiene la misión de comunicar a la ciudadanía cuál es la actividad del sistema político $\mathrm{y}$, fundamentalmente, cuáles son las políticas públicas que se están produciendo desde el gobierno.

Gracias a la comunicación de gobierno la "caja negra” podría volverse mucho más transparente. Es a partir de los mensajes enviados por el Estado desde donde la ciudadanía se forma una opinión sobre éste. La transparencia o fidelidad de las comunicaciones de gobierno está influida por una variable interviniente: los medios de comunicación. Y entonces surgen otras preguntas: ¿cómo se traslada la agenda de gobierno a la agenda de lo noticioso?, ¿hasta qué punto el Estado puede regular e intervenir en la agenda mediática?, ¿quién controla que la agenda de gobierno no sea manipulada en la construcción noticiosa?

El Estado comunica con todas sus acciones. Desde el proceso de recolección de basura, la prestación de servicios públicos, la solicitud de certificados o de registros, el pago de tributos e impuestos... siempre, de una u otra manera, el Estado está presente en el diario vivir de los ciudadanos. La comunicación atraviesa en forma transversal la gestión del Estado y, por ende, el trabajo en la cultura organizacional, los procesos de comunicación interna y el relacionamiento con la ciudadanía son temáticas de interés de la comunicación de gobierno. ¿Cómo ese gran leviathán concibe y gestiona las demandas de la ciudadanía? Una interrogante que queda abierta a la mejora de los procesos de atención al público en el Estado.

Para finalizar, es importante hacer hincapié en la pregunta sobre los espacios de participación ciudadana necesarios para que el punto de vista de la sociedad civil incida, efectivamente, en la toma de decisiones.

En este debate encontramos algunas interrogantes más: ¿cómo puede el ciudadano incidir en la agenda pública? ¿Qué ocurre con él en el proceso de formación de la agenda de gobierno? Juega un rol trascendental lo que se califique como asunto o ámbito público. Si entendemos por ámbito público a aquel que tiene la función de mediar entre Estado y sociedad, entre política y economía, entre constitución política y constitución real de una sociedad, entre la norma general y los intereses y necesidades particulares (Aguilar Villanueva, 1993), desde el Estado se pueden promover canales de participación ciudadana de manera de acrecentar la apropiación de la democracia por parte de sus propios soberanos.

Otro debate fundamental -y pendiente en nuestro país- es el que está en la base del gobierno electrónico y de la capacidad que tienen los ciudadanos del siglo XXI de manifestar su posición respecto a temas de la agenda pública desde su propio medio de comunicación. Un debate, sin dudas, del que tendremos que ocuparnos rápidamente. :-:
Bibliografia::

D. Altman: "Crisis de

gobernabilidad democrática: orígenes y mapa de lectura", en Instituciones y desarrollo, n. $8 / 9$ 2001, pp. 385-410.

A. Cánsales: La mediación mediada. Medios, estrategias de comunicación y sociedad civil.

JL. Cohen y Arato A.: Sociedad civil y teoría política, Fondo de la Cultura Económica, México, 2001.

J. Durán: "Estrategias de comunicación política para los gobiernos", en Estrategias de comunicación para gobiernos, OEA Washingotn DC, 2001.

R. Izurieta: "Comunicación de gobierno en la era del entretenimiento", en Estrategias de comunicación para gobiernos OEA, Washingotn DC, 2001.

C. Jackisch (comp.):

Representación política y democracia, CIEDLA, Buenos Aires, 1998.

D. McAdam, McCarthy J. y M. Zald, (Eds.): Movimientos sociales: perspectivas comparadas, Istmo Madrid, 1999

Pau Salvador I Peris: Comunicación e imagen en las $O N G$

<http://www.uji.es/bin/publ/edicio ns/jfi5/ong.pdf>

J. Peschard: La cultura politica (coord.), Colegio de Ciencia Política y Administración Pública, México, 1996.

O. Rincón: Comunicación política en América Latina, Centro de Competencia en Comunicación para América Latina, FESUR, Bogotá, 2004.

S. Tarrow: El poder en movimiento. Los movimientos sociales, la acción colectiva y la política, Alianza, Madrid, 1997 